\title{
PHARMACISTS' DISTRIBUTION IN NIGERIA; IMPLICATION IN THE PROVISION OF SAFE MEDICINES AND PHARMACEUTICAL CARE
}

\author{
YEJIDE OLUKEMI OSENI \\ Pharmacists Council of Nigeria, South West Zonal Office, Ibadan, Nigeria \\ Email: yejideoseni@yahoo.com
}

Received: 03 Jun 2017 Revised and Accepted: 31 Aug 2017

\begin{abstract}
Objective: The study appraised the distribution of pharmacists in the six (6) zones of Nigeria; determined the number of community pharmacies per population in each zone and in selected States; and assessed the implication of pharmacists' distribution in the provision of safe medicines and pharmaceutical care.

Methods: Register of pharmacists and pharmacies for 2013 and population estimate of 2013 were used to determine the percentage of pharmacists and number of community pharmacies per population in each zone. Interviews conducted for pharmacists were analyzed.

Results: About fifty-six percent (56.2\%) of all registered pharmacists works in the community pharmacies. Distribution of community pharmacists shows Southwest (SW) 41.7\%, Northcentral (NC) 20.6\%, Southsouth (SS) 15.5\%, Southeast (SE) 12.9\%, Northwest (NW) 6.7\% and Northeast (NE) $2.5 \%$. In SW zone where pharmacists are highly concentrated, rural/urban distribution of community pharmacies revealed urban $89.9 \%$ and rural $10.1 \%$, and a community pharmacy serviced 36,836 of the population. Inequitable distribution is due to low turn-out of graduate pharmacists, dearth of pharmacists abroad, poor remuneration, poor political will to employ pharmacists at the PHC level and poor amenities in the rural areas. This has led to the irrational use of medicines, non-professionals in practice, chaotic drug distribution system, poor access to safe medicines and negative effects on health indicators.
\end{abstract}

Conclusion: Improvement in the country economy, increasing number of faculties of pharmacy and improved facilities in the existing ones to increase turn-out of graduate pharmacists coupled with incentives for the establishment of rural community pharmacy will increase access to safe medicines and care in Nigeria.

Keywords: Pharmacists' distribution, Safe medicines, Pharmaceutical care

(c) 2017 The Authors. Published by Innovare Academic Sciences Pvt Ltd. This is an open access article under the CC BY license (http://creativecommons.org/licenses/by/4.0/) DOI: http://dx.doi.org/10.22159/ijpps.2017v9i10.20454

\section{INTRODUCTION}

The goals of the National Drug Policy (NDP) is to make available at all times to the Nigerian populace adequate supplies of drugs that are effective, affordable, safe and of good quality; to ensure the rational use of such drugs, and to stimulate the increased local production of essential drugs [1].

Proximity is an important component of access to healthcare services [2] and prompt access to essential medicines can improve health outcomes [3]. Access to medicines is affected by multiple factors including distribution of pharmacists and pharmacies. Hence, the objective of the NDP which is to ensure access to safe, efficacious, affordable and good quality medicines to every Nigerian and to promote rational use of such medicines is linked to the equitable distribution of health care facilities and professionals [1].

In Nigeria, public health facilities are inadequate to serve the population, hence the importance of community pharmacies as a potential access point to medicines. Drug storage and rational drug distribution channels in both public and private sectors and it's supply, sale and dispensing is under the control and supervision of pharmacists at all levels [1]. Pharmacists are therefore situated in the community to provide pharmaceutical services and pharmaceutical care which is the responsible provision of drug therapy for the purpose of achieving definite outcomes that improve a patient's quality of life [4]. Under pharmaceutical care comes the counseling to the patients about the health and medicine intake. Pharmacist naturally plays a vital role in explaining the medicinerelated issue well and in a better way [5]. Pharmaceutical care focuses the attitudes, behaviours, commitments, concerns, ethics, functions, knowledge, responsibilities and skills of the pharmacist on the provision of drug therapy with the goal of achieving definite therapeutic outcomes toward patient health and quality of life [6].
This study aimed to appraise the distribution of pharmacists in the six (6) geopolitical zones of Nigeria; determine the number of community pharmacies per population in each zone and in selected States, and assess the implication of pharmacists' distribution in the provision of safe medicines and pharmaceutical care.

This study is important because no published study had evaluated the geographical distribution of pharmacies and pharmacists in Nigeria and its effect on access to safe medicine. It is intended to help regulatory bodies and professionals in considering the challenge of distribution in Nigeria and possible solutions to it.

\section{MATERIALS AND METHODS}

This study was carried out between 2012 and 2014 in Nigeria. Nigeria, officially known as the Federal Republic of Nigeria, is a country that is located on the western coast of Africa with over five hundred different ethnic groups, many different languages, and declared its independence from the United Kingdom on October 1, 1960. The country features 36 states and its Federal Capital Territory (FCT), which is known as Abuja. It is divided into six (6) geopolitical zones [7].

Survey methods employed in collecting data for this study are document review of Pharmacists Council of Nigeria (PCN) register as at December 31, 2013 [8], National Population Commission, NPopC [9] census data and oral interviews and discussion from stakeholders to clarify issues. The PCN register as at December 31, 2013, was used to obtain the distribution of pharmacists and pharmaceutical premises in Nigeria. Nigeria was grouped into the six (6) existing zones while FCT was grouped into the North Central (NC) zone due to its proximity to the zone and realizing that the pharmacies there also serve other States in the NC zone. The Nigeria population data were obtained from the NPopC statistics while the 
2013 projection was obtained from the Central Intelligence Agency (US), CIA World Factsheet, July 2013 estimate [10]. The data were used to evaluate the correlation between the population and number of pharmacies in the country. The percentage of the pharmacies in each zone to total pharmacies was calculated and this was done to the population in each zone. The population estimate for 2013 and the PCN register of 2013 was used to develop a more comprehensive view of the present situation of the distribution and access to pharmacies in Nigeria. Urban and rural distribution were also assessed in the selected zone.

Within the period of the study, stakeholders had discussed at different fora including meetings and workshops relevant topics to this study, the challenges the distribution of pharmacists and pharmacies posed to access of safe medicines and how to overcome this challenges. The stakeholders were members of Pharmaceutical Inspector Committee (PIC) of PCN and Pharmaceutical Society of Nigeria (PSN). Members of PIC and PSN include pharmacists from all practice areas including community pharmacists, hospital pharmacists, and regulators, pharmacists in administration, academics, and industry. The interviews were unstructured and participants freely contributed on their views about the distribution and the effect on access to medicines in Nigeria. The World Pharmacists Day of 2012 was also centred on this topic of which the researcher was an active participant and resource person. Questions were centred on challenges the distribution posed on access to medicines; who services the people in the rural areas; what can pharmacists and government do to improve equitable distribution of pharmacists to improve access to medicines and pharmaceutical care among others.

Permission to use information in the PCN register was obtained. The qualitative research was observational in nature, hence permission was taken from stakeholders' organization including PSN and PIC involved in the discussion to publish the sessions relevant to this study. Informed consents from individuals members were not needed since their comments were observed and taken in their natural settings.

Table 1: Historical population of Nigeria

\begin{tabular}{|c|c|c|}
\hline Year & Pop. & $\pm \%$ p. a. \\
\hline 1952 & $30,403,305$ & - \\
\hline 1963 & $54,959,426$ & $+5.53 \%$ \\
\hline 1991 & $88,992,220$ & $+1.74 \%$ \\
\hline 2006 & $140,431,790$ & $+3.09 \%$ \\
\hline 2013 & $174,507,539$ & $+3.15 \%$ \\
\hline
\end{tabular}

Source: Central Intelligence Agency (US), CIA World Factsheet, July 2013 estimate

Table 2: Distribution of Nigeria population by State as at 2006 census

\begin{tabular}{|c|c|c|c|}
\hline State & Male & Female & Total (\%) \\
\hline Abia & $1,430,298$ & $1,451,082$ & $2,845,380[2.0]$ \\
\hline Adamawa & $1,607,270$ & $1,571,680$ & $3,178,950[2.2]$ \\
\hline Akwa Ibom & $1,983,202$ & $1,918,849$ & $3,902,051[2.7]$ \\
\hline Anambra & $2,117,984$ & $2,059,844$ & $4,177,828[2.9]$ \\
\hline Bauchi & $2,369,266$ & $2,283,800$ & $4,653,066[3.3]$ \\
\hline Bayelsa & 874,083 & 830,432 & $1,704,515[1.2]$ \\
\hline Benue & $2,114,043$ & $2,109,598$ & $4,253,641[3.0]$ \\
\hline Borno & $2,163,358$ & $2,007,746$ & $4,171,104$ [2.9] \\
\hline Cross River & $1,471,967$ & $1,421,021$ & $2,892,988[2.0]$ \\
\hline Delta & $2,069,309$ & $2,043,136$ & $4,112,445[2.9]$ \\
\hline Ebonyi & $1,064,156$ & $1,112,791$ & $2,176,947[1.5]$ \\
\hline Edo & $1,633,946$ & $1,599,420$ & $3,233,366[2.3]$ \\
\hline Ekiti & $1,215,487$ & $1,183,470$ & $2,398,957[1.7]$ \\
\hline Enugu & $1,596,042$ & $1,671,795$ & $3,267,837[2.3]$ \\
\hline Gombe & $1,244,228$ & $1,120,812$ & $2,367,040[1.6]$ \\
\hline Imo & $1,976,471$ & $1,951,092$ & $3,927,563[2.7]$ \\
\hline Jigawa & $2,198,076$ & $2,162,926$ & $4.361,002[3.1]$ \\
\hline Kaduna & $3,090,438$ & $3,023,065$ & $6,113,503[4.3]$ \\
\hline Kano & $4,947,952$ & $4,453,336$ & $9,401,288[6.6]$ \\
\hline Katsina & $2,948,279$ & $2,853,305$ & $5,801,584[4.1]$ \\
\hline Kebbi & $1,631,629$ & $1,624,912$ & $3,256,541[2.3]$ \\
\hline Kogi & $1,672,903$ & $1,641,140$ & $3,314,043[2.3]$ \\
\hline Kwara & $1,193,783$ & $1,171,570$ & $2,365,353[1.6]$ \\
\hline Lagos & $4,719,125$ & $4,394,480$ & $9,113,605[6.4]$ \\
\hline Nasarawa & 943,801 & 925,576 & $1,869,377[1.3]$ \\
\hline Niger & $2,004,350$ & $1,950,422$ & $3,954,722[2.8]$ \\
\hline Ogun & $1,864,907$ & $1,886,233$ & $3,571,140[2.6]$ \\
\hline Ondo & $1,745,057$ & $1,715,820$ & $3,460,877[2.4]$ \\
\hline Osun & $1,734,149$ & $1,682,810$ & $3,416,959[2.4]$ \\
\hline Оуо & $2,802,432$ & $2,778,462$ & $5,580,894[3.9]$ \\
\hline Plateau & $1,598,998$ & $1,607,533$ & $3,206,531[2.2]$ \\
\hline Rivers & $2,673,026$ & $2,525,690$ & $5,198,716[3.7]$ \\
\hline Sokoto & $1,863,713$ & $1,838,963$ & $3,702,676[2.6]$ \\
\hline Taraba & $1,171,931$ & $1,122,869$ & $2,294,800$ [1.6] \\
\hline Yobe & $1,205,034$ & $1,116,305$ & $2,321,339$ [1.6] \\
\hline Zamfara & $1,641,623$ & $1,637,250$ & $3,278,873[2.3]$ \\
\hline FCT Abuja & 733,172 & 673,067 & $1,406,239[1.0]$ \\
\hline
\end{tabular}

Source: National Population Commission (NPopC), 2006 


\section{RESULTS}

Table 1 shows the historical population of Nigeria since 1952. Census was last conducted in Nigeria in 2006 when the population was approximately 140 million people [9]. However, the projection for 2013 was about 179 million with $3.09 \%$ increase per annum by CIA [10]. The distribution of Nigeria population as per 2006 NPopC census is shown in table 2 . Kano State was ranked first $(6.6 \%)$ and followed closely by Lagos State (6.4\%) while the least ranked State was Bayelsa $(1.2 \%)$ apart from FCT. The distribution of 36 States according to 6 geopolitical zones is as shown in table 3. Four (4) of the zones including North Central (NC), North East (NE), South West (SW), and South-South (SS) has an average of six (6) States each present in zone while North West (NW) has the maximum of seven States and South East (SE) with minimum of five (5) States. Tables 4 and 5 show the distribution of licensed pharmacists and registered pharmaceutical premises in Nigeria using PCN 2013 Register. The Register indicated that $56.2 \%$ of pharmacists in Nigeria were community pharmacists while $19.6 \%$ were from the hospital pharmacy practice. The distribution of community pharmacists in the 6 zones shows that $41.7 \%$ of them were located in SW zone of
Nigeria. Table 5 also revealed that $59.8 \%$ of registered pharmaceutical premises were community pharmacies followed by $22.2 \%$ of wholesale outlets. The table also shows that $37.9 \%$ of the community pharmacies were located in SW zone of Nigeria. Urban/rural distribution of community pharmacies in SW zone of Nigeria as at 2013 as shown in table 6 shows that $89.9 \%$ were located in urban centres while $10.1 \%$ were in rural areas.

Table 7 shows the six (6) zones with the total population as at 2006 census and population projection per pharmacy for 2013. NW zone has the highest percentage of the population of $25.6 \%$ but second to the lowest in the percentage of community pharmacies (5.4\%). SW zone which was ranked second in the population $(19.7 \%)$ has the highest percentage of community pharmacies (37.9\%), hence a community pharmacy was estimated to service 36836 of the population followed by NC and FCT with 39752 population while in NE zone, a pharmacy service 425732 of the population. In SW zone, where most of the pharmacies were located (37.9\%), Lagos State was ranked highest in population (32.9\%) and in the number of community pharmacies $(74 \%)$, showing that a community pharmacy service 16361 of the population while other states in the zone were poorly serviced.

Table 3: The Nigeria 36 States within six (6) geopolitical zones

\begin{tabular}{ll}
\hline Zone & States \\
\hline North Central & Kogi, Niger, Benue, Nasarrawa, Plateau, Kwara \\
North East & Adamawa, Bauchi, Borno, Gombe, Taraba, Yobe \\
North West & Jigawa, Kaduna, Kano, Katsina, Kebbi, Sokoto, Zamfara \\
South West & Ekiti, Lagos, Ogun, Ondo, Osun, Oyo \\
South East & Abia, Anambra, Ebonyi, Enugu, Imo \\
South South & Akwa Ibom, Bayelsa, Cross River, Delta, Edo, Rivers \\
\hline
\end{tabular}

Source: Constitution of the Federal Republic of Nigeria, 1999.

Table 4: Distribution of licensed pharmacists and community pharmacists in six (6) zones as at December 31,2013

\begin{tabular}{|c|c|c|}
\hline Pharmacists' category & Total No. & $\%$ \\
\hline Academics & 243 & 2.4 \\
\hline Administrative & 402 & 3.9 \\
\hline Community & 5,739 & 56.2 \\
\hline Consultancy & 4 & 0.0 \\
\hline Hospital & 2,001 & 19.6 \\
\hline Industrial & 235 & 2.3 \\
\hline NYSC & 734 & 7.2 \\
\hline Unemployed & 840 & 8.2 \\
\hline Total & 10,240 & 99.8 \\
\hline Community pharmacist/Zone & Total no. & $\%$ \\
\hline North central & 1,882 & 20.6 \\
\hline North East & 145 & 2.5 \\
\hline North west & 382 & 6.7 \\
\hline South west & 2,395 & 41.7 \\
\hline South east & 742 & 12.9 \\
\hline South south & 893 & 15.5 \\
\hline Total & 5,739 & 100 \\
\hline
\end{tabular}

Source: Pharmacists Council of Nigeria (PCN) 2013 Register

Table 5: Distribution of registered pharmaceutical premises and retail/community pharmacies as at 2013 in six (6) zones as at dec 31, 2013

\begin{tabular}{|c|c|c|}
\hline Premises area of practice & Total no. & $\%$ \\
\hline Consultancy & 2 & 0.04 \\
\hline Distribution & 89 & 2.1 \\
\hline Importation & 487 & 11.5 \\
\hline Manufacturing & 186 & 4.4 \\
\hline Retail/community & 2,541 & 59.8 \\
\hline Wholesaling & 944 & 22.2 \\
\hline Total & 4,249 & 100.1 \\
\hline Community pharmacies/Zone & Total no. & $\%$ \\
\hline Northcentral & 655 & 25.8 \\
\hline North East & 57 & 2.2 \\
\hline North west & 137 & 5.4 \\
\hline South west & 962 & 37.9 \\
\hline South east & 254 & 10.0 \\
\hline South south & 476 & 18.7 \\
\hline Total & 2,541 & 100 \\
\hline
\end{tabular}

Source: Pharmacists Council of Nigeria (PCN) 2013 Register 
Table 6: Urban/rural distribution of community pharmacies in South West zone of Nigeria as at december 31, 2013

\begin{tabular}{llll}
\hline State & Urban N (\%) & Rural N (\%) & Total N (\%) \\
\hline Ekiti & $7(100)$ & $0(0)$ & $7(100)$ \\
Lagos & 637 & 75 & 712 \\
Ogun & 47 & 13 & 60 \\
Ondo & 28 & 1 & 29 \\
Osun & 52 & 4 & 56 \\
Oyo & 94 & 4 & 98 \\
Total & $865(89.9 \%)$ & $97(10.1 \%)$ & $962(100 \%)$ \\
\hline
\end{tabular}

Source: Pharmacists Council of Nigeria (PCN) 2013 Register

Table 7: Distribution of Nigeria population and community pharmacies in the six (6) zones of Nigeria and South West zone of Nigeria as at 2013

\begin{tabular}{|c|c|c|c|c|}
\hline Zone & $\begin{array}{l}\text { Population by } 2006 \\
\text { census }\end{array}$ & $\begin{array}{l}\text { Population projection } \\
\text { of } 2013(\%)\end{array}$ & $\begin{array}{l}\text { No. of registered community } \\
\text { pharmacies (CP) by Dec } 2013(\%)\end{array}$ & $\begin{array}{l}2013 \text { Population } \\
\text { estimate/pharmacy }\end{array}$ \\
\hline $\mathrm{NC}+\mathrm{FCT}$ & $20,369,956$ & $26,037,983(14.5)$ & 655 (25.8) & 39,752 \\
\hline NE & $18,984,299$ & $24,266,761(13.5)$ & $572.2)$ & 425,732 \\
\hline NW & $35,915,467$ & $45,909,100(25.6)$ & $137(5.4)$ & 335,103 \\
\hline SW & $27,722,432$ & $35,436,317$ (19.7) & 962 (37.9) & 36,836 \\
\hline SE & $16,395,555$ & $20,957,688(11.7)$ & $254(10.0)$ & 82,511 \\
\hline SS & $21,044,081$ & $26,899,686(15.0)$ & 476 (18.7) & 56,512 \\
\hline Total & $140,431,790$ & $179,507,539$ & 2,541 & 70,644 \\
\hline \multicolumn{5}{|c|}{ South West } \\
\hline Ekiti & $2,398,957$ & $3,066,477$ (8.7) & $7(0.7)$ & 438,068 \\
\hline Lagos & $9,113,605$ & $11,649,505$ (32.9) & $712(74.0)$ & 16,361 \\
\hline Ogun & $3,751,140$ & $4,794,911(13.5)$ & $60(6.2)$ & 79,915 \\
\hline Ondo & $3,460,877$ & $4,423,880(12.5)$ & $29(3.0)$ & 152,547 \\
\hline Osun & $3,416,959$ & $4,367,743(12.3)$ & $56(5.8)$ & 77,995 \\
\hline Oyo & $5,580,894$ & $7,133,802(20.1)$ & $98(10.2)$ & 72,794 \\
\hline Total & $27,722,432$ & $35,436,317$ & 962 & 36,836 \\
\hline
\end{tabular}

\section{Analysis of stakeholders' discussion}

Stakeholders were of the opinion that pharmacists are unevenly distributed across the country and in States where they are concentrated, they are more concentrated in urban areas. They gave the following reasons for pharmacists and community pharmacies uneven distribution in Nigeria:

- Average number of turnout of graduate pharmacists from Schools of Pharmacy cannot meet the demand for pharmacists in Nigeria

- Pharmacists are inadequate in number to cover the population of about 170 million Nigerians

- The dearth of pharmacists due to search for greener pasture abroad also contributed to the inadequate number of pharmacists to cover the country.

- Above is coupled with poor remuneration for pharmacists despite their inadequacy in service, hence some pharmacists had diverted to another profession

- Rural areas are not serviced by pharmacists due to poor social amenities in such areas

The implication of the uneven distribution of pharmacists and community pharmacies in access to safe medicine and pharmaceutical care

- The government recognized the uneven distribution, hence the establishment of patent medicine vendors (PMVs) in underserved areas

- However, PMVs are now struggling to be in urban areas, thus competing with pharmacies

- Though PMVs have limited scope of medicines to sell as stated in the drug list, they often stock medicines that are beyond their scope

- Inability of pharmacists to take up their responsibilities as custodians of medicines and in servicing the populace had given unqualified persons to take up their position
- Handling of medicines especially ethicals by non-professionals and unqualified persons in case of PMVs has caused more damage than good to the health of the populace and has led to the following:

i. Irrational use of medicines

ii. Medicines do not follow the appropriate channel of distribution and this had led to chaotic drug distribution

iii. Increase distribution of fake and counterfeit medicines in circulation

iv. Misuse and abuse of medicines

v. increased morbidity and mortality rates

- Restriction of pharmacists from double practice in our law has affected pharmacists optimizing their capacity as healthcare professional

Suggested solutions to uneven distribution of pharmacists in Nigeria:

- PCN should accredit more faculties of pharmacy to train more graduate pharmacists

- Facilities in the existing faculties of pharmacy should improve to accommodate more students for training

- Government should engage pharmacists in PHC and improve on their remuneration so as to serve people in the rural areas

- Government should improve the amenities in rural areas so as to serve as incentives for opening of community pharmacies in the rural areas

- Political will to sanitize the profession by ensuring that only pharmacists and its sub-cadre (the Pharmacy Technicians) handle medicine

- PMVs should be in rural areas only to fill the gaps in providing medicines in underserved areas and be enforced to handle simple household medicines only as in their drug list 
- Pharmacists working in hospitals, administration, and academia should be allowed to own community pharmacies and open after the close of work while locum pharmacists can cover for them during the hours of their duty

- Pharmacists in academia believed that obtaining an annual license to practice without being given an opportunity to practice is a waste of resources. However, being allowed to practice which will expose them to current drugs will give them more leverage to impact the knowledge on their students

\section{DISCUSSION}

Most pharmacists (56.2\%) in Nigeria are in community pharmacy practice as shown from the 2013 PCN Register (table 4). This record is similar to what was observed in a report by FIP in 2006[11] where majority of pharmacists in the 34 countries under study practice in the community setting hereby Europe has the highest percentage of $71 \%$, followed by Pan America (66.28\%), Africa/East Mediterranean (66.23\%) and Asia (51.67\%).

The skew distribution of community pharmacists was evidence in the data as presented from the PCN register where $41.7 \%$ of the community pharmacists are located in SW zone. Lagos State housed a metropolitan city is located in SW zone of Nigeria and was ranked

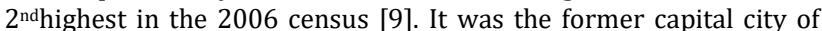
Nigeria and is still the business hub of Nigeria. Hence there is a drive for professionals to settle in this state and some other neighbouring States to it like Ogun and Oyo States whereby some other states and zones were deprived.

Geographical distribution of pharmacies has consequences for rural and deprived areas and patients with reduced mobility. Even though $59.8 \%$ of all registered premises in Nigeria are community pharmacies, $37.9 \%$ of them are concentrated in the SW zone followed by NC and FCT (25.8\%) and $18.7 \%$ in SS zone (table 5). Pharmacists provide important pharmaceutical services to patients including dispensing of medicines, counselling of patient and provision of pharmaceutical care. The location of these services and the accessibility of community pharmacies is an important determinant of health care access and related quality of service provided [2]. Poor accessibility, for example, can cause prescription to go unfulfilled thus leading to the irrational use of medicines, hence geographical access to pharmacies is important to ensure access to medicines and related professional services.

The PCN data also shows that even in SW zone where community pharmacies are most concentrated, they are mostly concentrated in urban centres leaving the rural areas underserved. Research has shown that areas with teaching hospitals and a population that can afford to pay for health services invariably attract more health workers than region without such. Hence health workers density is generally highest in urban centres than rural areas [12].

Stakeholders were of the opinion that government can attract pharmacists to rural areas by improving the social amenities in such area and given incentives to those that want to settle there. This is in compliance with the study of Law et al. (2011) who suggested that government should seriously consider implementing mechanisms such as provision of professional compensation for those pharmacists in rural and remote areas as applicable in Australia and Ontario [13]. Incentives can also include provision of minimal rent in a government building or to contract services to private pharmacies, guaranteeing a certain income and with the priority of contract renewal [14].

The Stakeholder concurs that the total number of licensed pharmacists in Nigeria cannot service the population of about 170 millions of Nigeria. Even though Nigeria has no standard of the number of pharmacies or pharmacist to a population as some other countries do, the PCN data matched across the population revealed that in SW zone where community pharmacies are most concentrated (table 7), one community pharmacy serviced 36,836 of the population whereby in Lagos State where we have the highest number of community pharmacies, one community pharmacy still service 16357 of the population if evenly distributed. The number of health workers per 10,000 population, by cadre-is the health workforce indicator that is most commonly reported internationally and represents a critical starting point for understanding the health system resources situation in a country [15]. Studies showed that many countries have laws adjusting pharmacy distribution. These include Saudi Arabia [16], Iran which set one daily pharmacy for every 6,000 people [17], South Africa; 1 per 10,000 benchmarks [18] and Canada [2] while Pakistan also recommended 5 pharmacists per 10,000 population [19].

Lack of trained pharmacy staff is a bottleneck in national effort to improve access to medicines in the community and primary healthcare delivery [3]. Stakeholders were able to identify that the inadequacy of pharmacists had caused the government to allow the patent medicine vendors to handle simple household medicines called OTC which they most of the time exceed the limit by stocking prescription medicines. This delegation to untrained vendors whose eligibility is only able to read and write has led to adverse consequences for patients. Hence the stakeholders suggested the need to increase pharmacist workforce in Nigeria through accreditation of more faculties of pharmacy and also increase in facilities of the existing ones to accommodate more pharmacy students. They noted that having a trained pharmacy workforce to manage the supply chain and safely dispense medicines is critical to ensuring timely access to safe medicines and pharmaceutical care. Also, having sufficient numbers of well-trained and motivated human resources is essential for a robust health system [20]. This is in compliance with the stakeholders' further suggestion on the need to improve pharmacists' remuneration to prevent a dearth of pharmacists abroad.

Pharmacists working in hospitals, administration, and academia also believed that they should be allowed to own community pharmacies and open after the close of work while locum pharmacists can cover for them during the hours of their duty. This, they believe will be a stopgap solution to improve access to medicine and pharmaceutical care rather than leaving the service in the hands of quacks and untrained personnel.

Expert perception on the extent to which regulation can improve the geographical distribution of community pharmacies was discussed in a study from South Africa [2] where they concur that regulation can improve the geographical distribution of community pharmacies. As earlier stated, setting law for the number of pharmacies that can serve a particular population is not yet in existence in Nigeria. However, restriction to location of new pharmacies is applicable in Nigeria where location of new pharmacies is based on the minimum distance of $200 \mathrm{~m}$ to another existing registered pharmacy [21]. This rule in Nigeria is not out of place for spread on the location of premises as it is in existence in some other countries including the EU States [22] and South Africa. Hence stakeholders urged that this regulation for establishing a pharmacy should be binding to prevent risk of irregular distribution.

Lack of enforcement of regulation on entry to the market in terms of patent medicine vendors selling prescription medicines is another issue identified by the stakeholders that also affect access to safe medicines. Handling of ethicals by PMVs is discovered to increase access to distribution of fake and counterfeit medicines through unidentified channel which continues to cause serious public health problems in many countries around the globe, particularly in the African countries which are their major consumers [23]. This also leads to chaotic channel of distribution of medicines. They suggested that the implementation of the National Drug Distribution Guidelines [24] is paramount to access to safe medicine which stipulated qualified persons and channel of distribution of medicines while enforcement should be boosted up by the regulatory bodies to ensure that PMVs comply with laws, regulations, and guidelines and only be registered in underserved area.

The study is a novel study in Nigeria on which other research in this area can be built upon as no published study has evaluated the distribution of pharmacists in Nigeria and its implication to provision of safe medicines and pharmaceutical care. However, some limitations were observed in the study. Census was not conducted in the year 2013, hence an estimated data was used which might not be a representation of the 2013 population. The stakeholders' views were consensuses of opinions of the pharmacists reached under the meetings and workshops under review and not individual opinions of respondents. Likewise, the 
consensuses of opinion were those of the stakeholders at SW zone of Nigeria where the researcher is based and may not totally represent the opinions of other stakeholders in another part of the country where there are few pharmacists and more challenges. Hence the result is open to bias and may not be a representation of the whole population and cannot be generalized.

\section{CONCLUSION}

The study concluded that distribution of community pharmacists and pharmacies is highly skewed as shown in the PCN Register and there is significant difference between rural and urban distribution of pharmacies in Nigeria. It also concluded that pharmacy distribution is not proportionate to the population in all the six zones of Nigeria hence the available community pharmacies is very inadequate to service the Nigeria population as evidence in the 2013 population estimate per pharmacy.

Stakeholders, therefore, suggested increase in graduate pharmacists' turnout through accreditation of more schools of pharmacy and improve facilities in the existing schools to accommodate intake of more students. They further suggested improvements in country economy reduce dearth of pharmacists abroad and in pharmacists' remuneration to prevent diversification of pharmacists to another area of profession while Government and the professional association should design incentives to attract pharmacists to rural areas.

The regulatory body needs to be involved in the mapping of registered community pharmacies so as to have the true picture of the distribution across the country and to set standard for one pharmacy per a particular population in Nigeria as in many other countries. This will help in further distribution processes. The regulatory body should also implement regulation, guidelines, and policies that relate to access to safe medicines in Nigeria to improve equitable distribution of pharmacies across the country. These include enforcement of the existing regulation of $200 \mathrm{~m}$ between community pharmacies, guidelines on issuance of patent medicines license and possible review of the eligibility of vendors and compliance to drug list.

\section{ACKNOWLEDGEMENT}

My appreciation goes to my boss Pharm. N. A. E. Mohammed, Registrar, Pharmacists Council of Nigeria forgiven me free hand to carry out this study.

\section{AUTHOR CONTRIBUTION}

Oseni YO contributed to the study concept, design, collection, analysis, and interpretation of data. She also contributed to the preparation of the manuscript and its revision.

\section{CONFLICTS OF INTERESTS}

The author declares that there is no conflict of interest

\section{REFERENCES}

1. Federal Ministry of Health/World Health Organisation. National Drug Policy, First Revision; 2003.

2. http://apps.who.int/medicinedocs/documents/s16450e/s164 50e.pdf. [Last accessed on 29 Jun 2017]

3. Law MR, Dijkstra A, Douillard JA, Morgan SG. Geographic accessibility of community pharmacies in Ontario. Healthcare Policy 2011;6:36-45.

4. Lubinga SJ, Jenny AM, Larsen-Cooper E, Crawford J, Matemba C, Stergachis A, et al. Impact of pharmacy worker training and deployment on access to essential medicines and health outcomes in Malawi: protocol for a cluster quasi-experimental evaluation. Implement Sci 2014;9:156.

5. Hepler CD, Strand LM. Opportunities and responsibilities in pharmaceutical care. Am J Hosp Pharm 1990;47:533-43.

6. Nafiu A, Mahmud SG. The eminent threats of counterfeit drugs to quality health care delivery in Africa: Updates on consequences and way forward. Asian J Pharm Clin Res 2017;10:82-6.

7. Commission to Implement Change in Pharmaceutical Education. A position paper Entry-level Education in
Pharmacy: A Commitment to Change. American Association of Colleges of Pharmacy News. Special Report. Alexandria VA 1991. Available from: http://www.aacp.org/resources/ historical documents/Documents/COMMISSPOSPAPER3.pdf. [Last accessed on 29 Jun 2017]

8. Constitution of the Federal Republic of Nigeria; 1999. Available from: http://www.nigeria-law.org/Constitution Of The Federal RepublicOfNigeria.htm. [Last accessed on 03 Jun 2017]

9. Pharmacists Council of Nigeria. List of Registered Premises and Pharmacists. Pharmacists Council of Nigeria; 2013.

10. National Population Commission (NPopC). National Results: Population by State and Sex; 2006. Available from: http://www.population.gov.ng/index.php/state-population. [Last accessed on 29 Jun 2017]

11. Central Intelligence Agency. CIA World Factsheet; 2013. Available from: https://www.cia.gov/library/publications/theworld-factbook/geos/ni.html. [Last accessed on Jun 3 2017]

12. International Pharmaceutical Federation. Global Pharmacy Workforce and Migration Report; 2006. Available from: www.fip.org/files/fip/HR/final report/Part1.pdf. [Last accessed on 29 Jun 2017]

13. World Health Organisation. The world health report: working together for health; 2006. Available from: http://www.who.int/whr/2006/en/. [Last accessed on $26 \mathrm{Apr}$ 2017].

14. Mossialos E, Mrazek M, Walley T. Regulating Pharmaceuticals in Europe: striving for efficiency, equity and quality. Maidenhead (UK): McGraw-Hill International; 2004.

15. Ward K, Sanders D, Leng H, Pollock AM. Assessing equity in the geographical distribution of community pharmacies in South Africa in preparation for a national health insurance scheme. Bull World Health Organ 2014;92:482-9.

16. World Health Organisation. Monitoring the building blocks of health systems: a handbook of indicators and their measurement strategies; 2006. Available from: http://www.who.int/healthinfo/systems/WHO_MBHSS_2010_f ull_web.pdf. [Last accessed on 26 Apr 2017]

17. Najjar T. Study on the distribution of community pharmacies in Riyadh, Saudi Arabia. J Soc Adm Pharm 2003;20:72-6.

18. Kebriaeezadeh A, Eslamitabar SH, Khatibi M. Iranian pharmaceutical law and regulations, 2nd ed. Razi distribution; 2008. p. 199-206.

19. Gilbert L. Community pharmacy in South Africa: a changing profession in a society in transition. Health Place 1998;4:273-85.

20. Ministry of Health. Pakistan Pharmaceutical Country Profile. Government of Pakistan Islamabad; 2010. Available from: www.who.int/medicines/areas/coordination/pakistan.pdf. [Last accessed on 29 Jun 2017]

21. Management Sciences for Health: MDS-3: Managing Access to Medicines and Health Technologies. Arlington, VA: Management Sciences for Health; 2012. Available from: http://www.msh.org/sites/msh.org/files/mds3-jan2014.pdf. [Last accessed on 11 Sep 2014]

22. The government of Nigeria. Pharmacists Council of Nigeria: Inspection, Location, and Structure of Pharmaceutical Premises, Regulation; 2005. p. 79.

23. Volkerink B, de Bas P, van Gorp N, Philipsen NJ. Study of regulatory restrictions in the field of pharmacies: Main report. Rotterdam: Ecorys; 2007.

24. Karthikeyan G, Ranganayakulu D. Benefits of clinical pharmacists pharmaceutical care intervention to quality of patient's life and control hypertension. Asian J Pharm Clin Res 2014;7:223-6.

25. Federal Ministry of Health. National Drug Distribution Guidelines (NDDG). 2nd ed. Federal Ministry of Health; 2012.

\section{How to cite this article}

- $\quad$ Oseni, Yejide Olukemi, Yejide Olukemi Oseni. Pharmacists' distribution in nigeria; implication in the provision of safe medicines and pharmaceutical care. Int J Pharm Pharm Sci 2017;9(10):49-54. 